\title{
Sputter Deposition of Nanocones for Field Emission
}

\author{
Alan F. Jankowski \\ Jeffrey P. Hayes
}

This paper was prepared for submittal to the Materials Research Society 1997 Spring Meeting

April 2, 1997

San Francisco, CA

July 1997

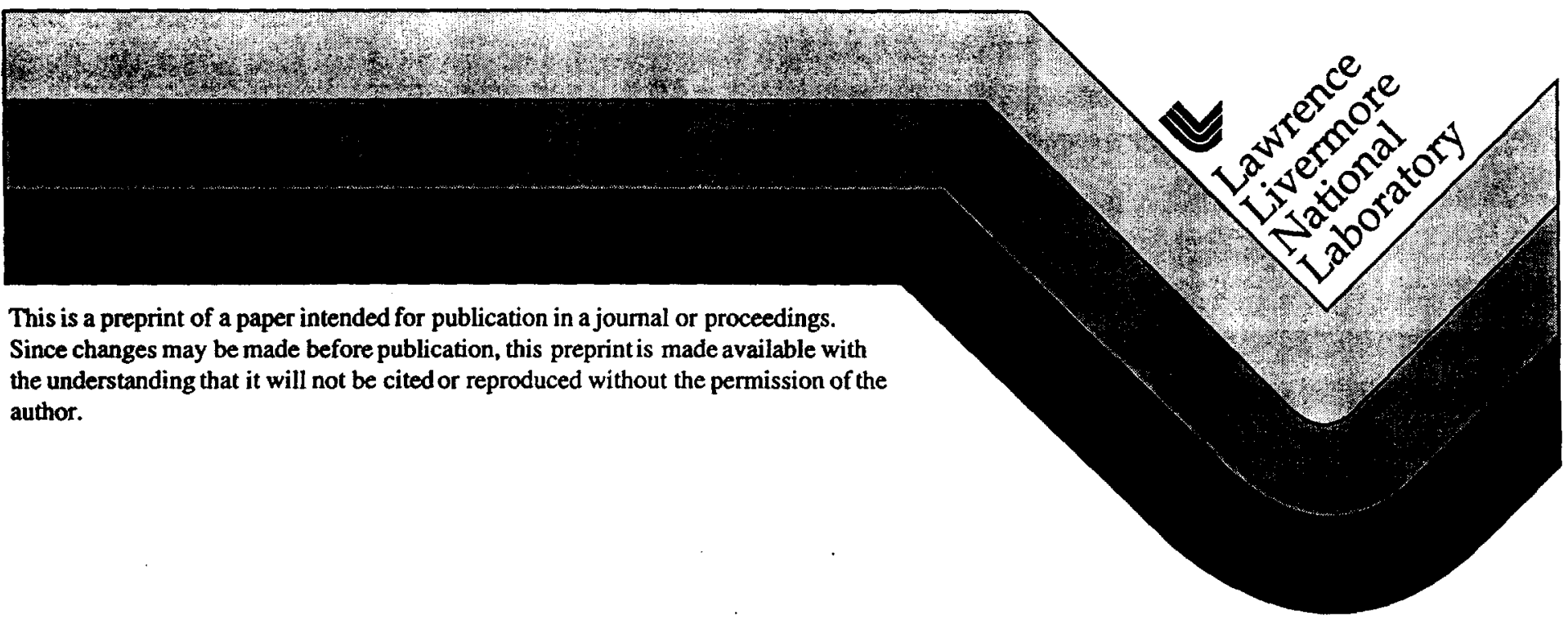




\section{DISCLAIMER}

This document was prepared as an account of work sponsored by an agency of the United States Government. Neither the United States Government nor the University of California nor any of their employees, makes any warranty, express or implied, or assumes any legal liability or responsibility for the accuracy, completeness, or usefulness of any information, apparatus, product, or process

disclosed, or represents that its use would not infringe privately owned rights. Reference herein to any specific commercial product, process, or service by trade name, trademark, manufacturer, or otherwise, does not necessarily constitute or imply its endorsement, recommendation, or favoring by the United States Government or the University of California. The views and opinions of authors expressed herein do not necessarily state or reflect those of the United States Government or the University of California, and shall not be used for advertising or product endorsement purposes. 


\title{
SPUTTER DEPOSITION OF NANOCONES FOR FIELD EMISSION
}

\author{
Alan F. Jankowski and Jeffrey P. Hayes \\ University of California - Lawrence Livermore National Laboratory \\ P.O. Box 808, Livermore, CA 94550
}

ABSTRACT

Deposition into micron-sized holes is known to produce cone shapes as supported on substrates. Potential uses for the cones include field-forming devices as field ionizers and field emission cathodes. The application of such devices include flat panel displays and flash $x$-ray tubes. Process iterations to closely space arrays of sharp cones have been extensively documented during the past two decades using the physical vapor deposition method of evaporation. Sputter deposition is well known as a method to fill holes and trenches but has only recently been demonstrated as an alternative method to produce field emission cathodes. In a further reduction in size, we have been successful in demonstrating the ability to deposit a cone shape into a cavity with a $300 \mathrm{~nm}$ diameter hole. Through comparison to the results of electron-beam evaporative deposition, a sputter deposited nanocone appears to be suitable for use as a field emission cathode.

\section{INTRODUCTION}

The need for electron sources to use in vacuum microelectronics is met with the development of cathodes that have characteristics of cold emission, low voltage operation, high current density and microscopic size. Conventional vacuum processing of the metallization steps used in microelectronic devices have focused on evaporation techniques to produce the size and shape required for efficient cathodes. A typical field emission device consists of a thin-film layered structure. An insulating layer is formed between two conductors. Holes in the the top conducting film allow for etching into the insulating layer to create a cavity. Exposure to a vapor flux then produces a deposited structure with its base in contact with the bottom conducting layer. The objective to fill a micron-sized hole with a metal vapor to form the cone-shaped cathode are traditionally met with the use of evaporation as produced with an electron beam. 1,2 The line-of-sight requirement for the vapor flux places constraint on the use of conventional sputter 
deposition into micron gated holes. Most sputter deposition sources produce a vapor plume which is not line-of-sight but divergent beyond the mean-free path of the sputtered neutral. The desire to decrease the micron-sized hole to achieve a greater packing density of emitters in an arrayed pattern wasrecently accomplished in a reduction to a $320 \mathrm{~nm}$ tipto-tip spacing of emitters. ${ }^{3}$ Certainly, the use of sub-micron spacing does not decreases the difficulties encountered for vapor deposition through small diameter gates and subsequent formation of a suitable submicron-sized, cathode shape.

\section{EXPERIMENTS AND RESULTS}

The basic features of a field emission device are: (i) a conductive substrate -- for example, Si with a metallization layer; (ii) an insulator -- for example, a $\geq 0.2 \mu \mathrm{m}$ thick $\mathrm{SiO}_{2}$ layer; (iii) the gate (anode) -- for example, a $0.1-0.3 \mu \mathrm{m}$ thick refractory metal layer with a cavity opening diameter of $\leq 1 \mu \mathrm{m}$; and (iv) the cathode -- for example, a coneshaped refractory metal as Mo.

The present approach is based on provision for line-of-sight sputter deposition of the cone-shaped cathodes through small diameter holes. A collimator is designed and used to control the divergence of the vapor flux from the planar magnetron sources. $4,5 \mathrm{~A}$ direct comparison of images can be made between the cathodes deposited using electron beam evaporation (Fig. 1) and planar magnetron sputter deposition (Fig. 2). The aspect ratio of each cone is similar to the intent of positioning the cathode tip within the gate. Whereas the nanocone deposited using evaporation has a fibrous structure produced at an elevated temperature $>250^{\circ} \mathrm{C}$, the sputter deposited nanocone has a dense fine-grained structure produced at a $<50^{\circ} \mathrm{C}$ substrate temperature. The difference in grain structure is not reflected in the smaller tip radius for the evaporated nanocone which may offer an advantage for emission performance at low voltage. Whereas moderate substrate heating is required for adhesion of the evaporated nanocone, the sputtered nanocone is adherent at room temperature.

Emission from the sputter deposited cones has been measured (Fig. 3) confirming that the cathodes function, although not yet optimally. With suitable approximations, the Fowler-Nordheim analysis of the $\mathrm{i}-\mathrm{V}$ behavior is used to determine the cathode emission area $(\alpha) .2,6,7$ For field emission, the $\ln \left(\mathrm{i} / \mathrm{V}^{2}\right)$ vs $(1 / \mathrm{V})$ plot yields a straight line with slope (-b) and intercept (a) that are used to compute an effective area ( $\alpha$ ) equivalent to $7.64 \mathrm{ab}^{2}\left(\mathrm{~nm}^{2}\right)$. A nanometric-scaled $\alpha$ is reported for micron-size, cone-shaped cathodes fabricated by evaporation. ${ }^{2}$ Elsewhere, significantly larger values of $\alpha\left(10^{1-10^{2}} \mathrm{~nm}^{2}\right)$ are 
reported for micron-size, cone-shaped cathodes fabricated by collimated, hollow-cathode sputter deposition. ${ }^{5}$ The leveling of current with voltage (in the 45-55 V region of Fig. 3) correlates to a disruption in field emission from the sputter deposited cathodes. The effect is indicated by an offset in the curve of the Fowler-Nordheim plot (Fig. 4) which yields parallel-line segments at low and higher voltage. The area $\alpha$ per sputtered nanocone is $<10^{-1} \mathrm{~nm}^{2}$ which suggests only a few percent of the cathodes emit and not yet efficiently at this point in time.

Several features that facilitate cathode synthesis can be incorporated into a sputter depositon process. ${ }^{4}$ (1) The parting-layer deposition can proceed using an inert or reactive gas at variable angles of grazing incidence from the substrate plane. The parting layer serves to protect the insulator cavity walls and allows for easy removal of the residual metallization after the cathode formation step from the top surface of the gate metal. (2) The use of multiple parting-layer sources will facilitate uniform closure of the gate hole producing a spherical symmetry to the forming cone whereas one parting-layer source can often produce an elliptically shaped cone which may be undesireable. (3) A variable source-to-substrate separation can be featured in the collimated and ratecontrolled cathode deposition. (4) The use of a collimated vapor flux provides for "lineof-sight" deposition wherein the collimator design corresponds specifically with the type of sputter source (for example, hollow cathode versus planar), the source-to-substrate geometry including collimator position, and the additional required shielding. (5) The optional use of multiple deposition sources accompanied with substrate motion.

\section{SUMMARY}

We have demonstrated the ability to deposit a cone shape into a cavity with a $300 \mathrm{~nm}$ diameter hole. With comparison to cathodes formed by electron-beam evaporation, a sputter-deposited nanocone shows field emission at $25 \mathrm{~V}$ and appears to offer promise for use in devices as flat panel displays or flash $\mathrm{x}$-ray tubes. Sputter deposition offers a greater range of process conditions with which to produce field emission cathodes. The use of a lower substrate temperature offers process advantages for handling and scaling as well as easing adhesion concerns. Sputtering can be accomplished with an inert gas as argon or using reactive gases. A wide range of target materials are accessible, consisting of different elemental metals, as $\mathrm{Ni}, \mathrm{Mo}, \mathrm{Ti}, \mathrm{W}$, etc. or metal alloys as well as metal-nitrides, ${ }^{7}$ metal-carbides, ${ }^{8}$ etc. Further in-situ, postdeposition processing can be advantageous to extend the service life of the cathode. For 
example, the surface can be conditioned using plasma immersion wherein a bias voltage applied to the cathode implants gaseous elements as ionized nitrogen. The sputtering process appears promising as an alternative to electron beam evaporation of metal layers as required for the formation of the cone-shaped cathode.

\section{ACKNOWLEDGMENTS}

We thank Jeff Morse, et al. of the Microelectronics Center for providing the substrate wafers and Jim Yoshiyama for the scanning electron microscopy imaging. Also, we thank Chris Spindt, et al. of Candescent Technology for the emission measurements. This work was performed under the auspices of the United States Department of Energy by Lawrence Livermore National Laboratory under contract \#W-7405-Eng-48.

\section{REFERENCES}

1. C.A. Spindt, J. Appl. Phys. 39, 3504 (1968).

2. C.A. Spindt, I. Brodie, L. Humphrey and E.R. Westerberg, J. Appl. Phys. 47, 5248 (1976).

3. C.O. Bozler, C.T. Harris, S. Rabe, D.D. Rathman, M.A. Holis and H.I. Smith, J. Vac. Sci. Technol. B 12, 629 (1974).

4. A.F. Jankowski and J.P. Hayes, "Sputter Deposition of a Field Emission Cathode", DOE Patent Docket No. S-81642 (RIL-12765), LLNL Docket No. IL-9535 (1994).

5. G.N.A. van Veen, B. Theunissen, K. van de Heuvel, R. Horne and A.L.J. Burgmans, J. Vac. Sci. Technol. B 13, 478 (1995), see also European Patent Application No. 93200841.0 (1993).

6. R.H. Fowler and L.W. Nordheim, Proc. R. Soc. London A 119, 173 (1928). 
7. W.K. Lo, G. Parthasarathy, C.W. Lo, D.M. Tanenbaum, H.G. Craighead and M.S. Isaacson, J. Vac. Sci. Technol. B 14, 3787 (1996).

8. W.A. Mackie, R.L. Hartman, M.A. Anderson and P.R. Davis, J. Vac. Sci. Technol. B 12, 722 (1994).

\section{FIGURE CAPTIONS}

Fig. 1. A cross-section view of a Mo nanocone deposited by electron beam evaporation.

Fig. 2. A cross-section view of a Mo nanocone deposited by sputter deposition.

Fig. 3 The current (i) - voltage (V) emission output from a sputter-deposited Mo nanocone.

Fig. 4 The Fowler-Nordheim plot of field emission from the sputter-deposited Mo nanocone. 


$$
a
$$




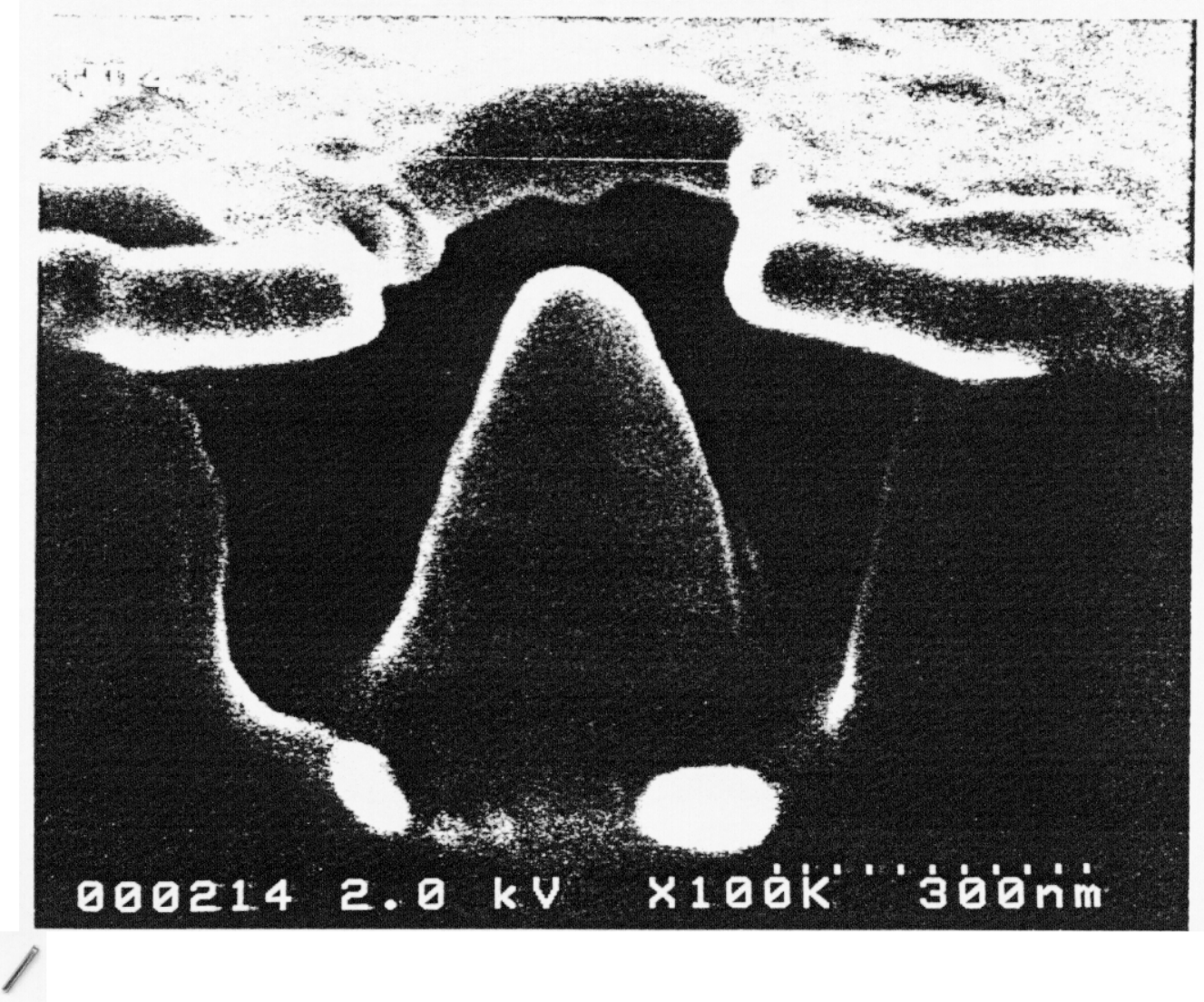




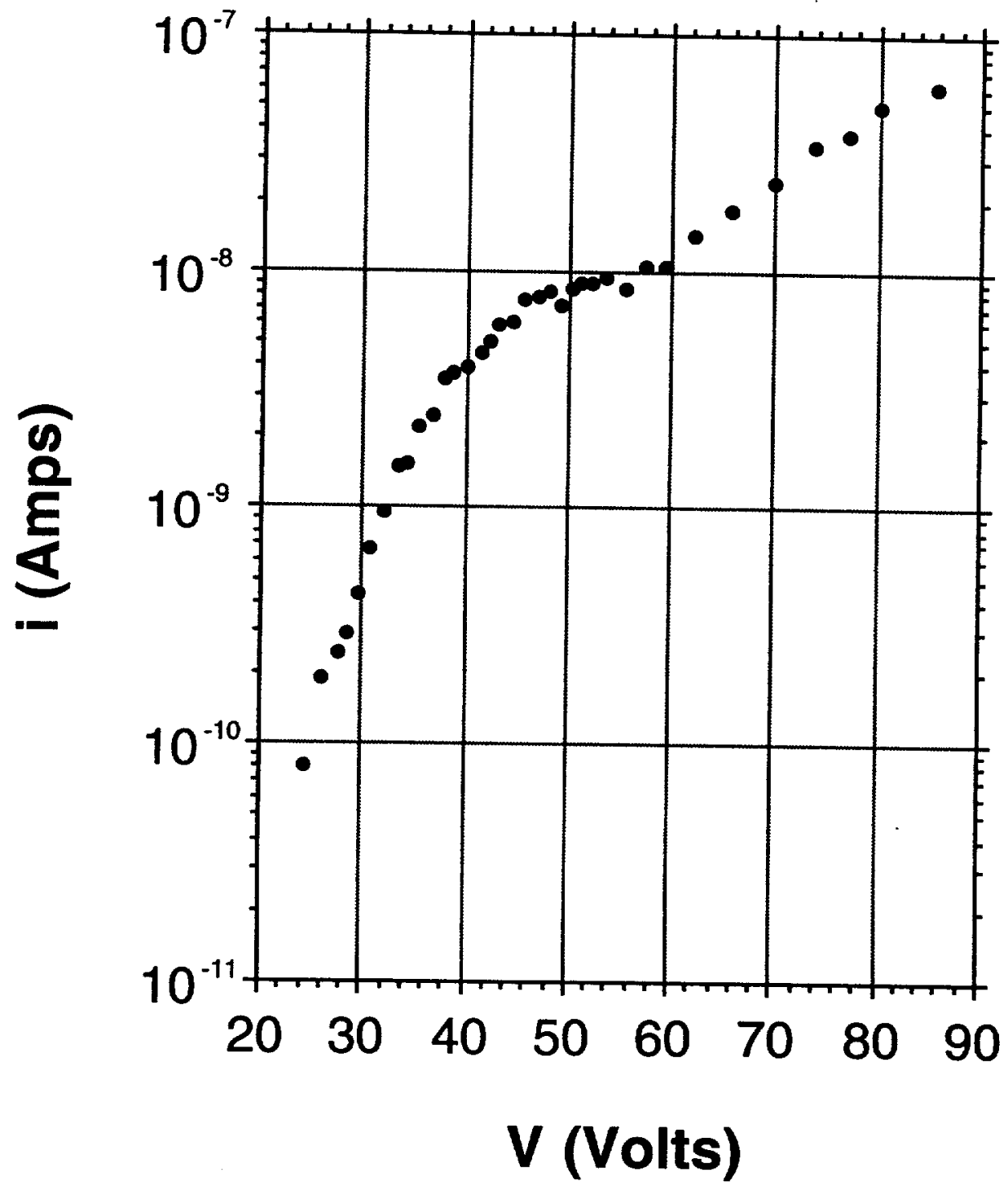




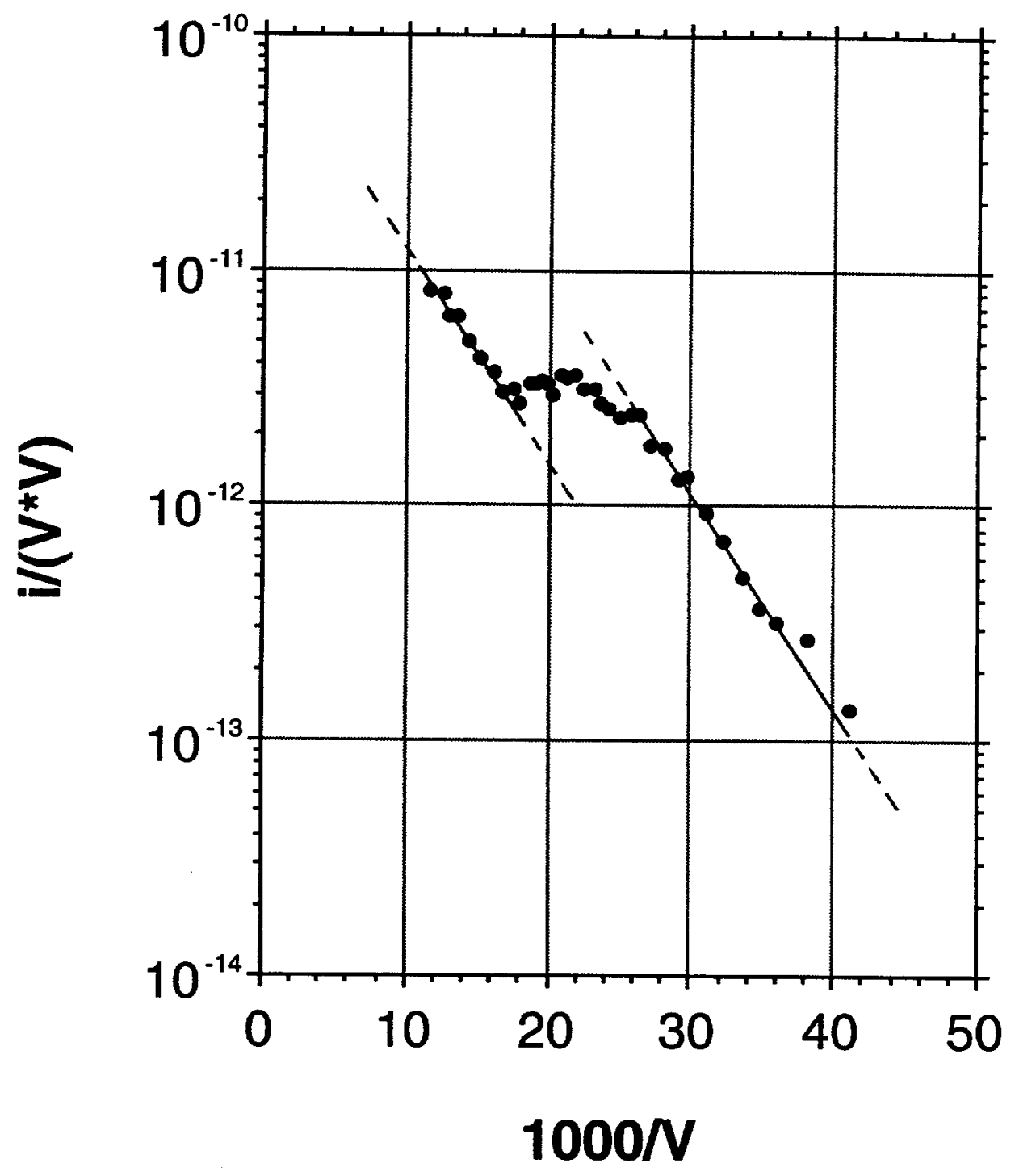




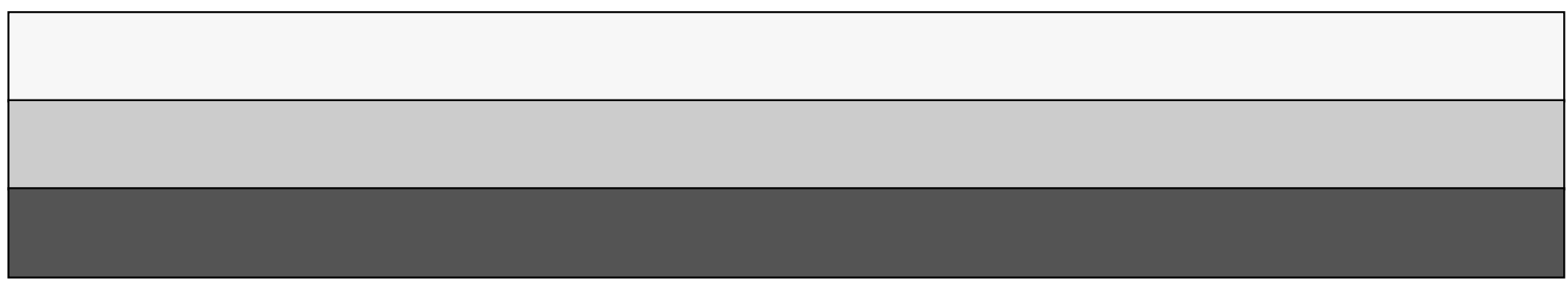

